\title{
REFLEXIONES SOBRE LA GLOBALIZACIÓN, POBREZAY DESARROLLO: INCIDENCIA EN LAS ORGANIZACIONES DE ECONOMÍA SOCIAL
}

\author{
POR \\ $\mathrm{M}^{\mathrm{a}}$ Elena INGLADA GALIANA ${ }^{1} \mathrm{y}$ \\ José Manuel SASTRE CENTENO ${ }^{2}$
}

\section{RESUMEN}

La Globalización a partir de las dos últimas décadas del siglo XX y los años que han transcurrido del XXI, se ha consolidado como una realidad que, de una manera u otra, ha configurado la economía actual y, en buena parte, las condiciones de vida de todo el planeta. $\mathrm{Su}$ relación con el desarrollo es directa ya que este ha sido una condición para aquella, y la globalización el marco en que este ha sido posible. Por lo general se identifica el desarrollo con la expansión y esta con un mercado cada vez más amplio hasta llegar a la globalización. Pero en esta ecuación macroeconómica ¿dónde queda la pobreza? Pues en el centro de la interacción entre globalización y desarrollo. La pobreza es el elemento necesario para el desarrollo y, por ende, para la globalización.

En este trabajo intentaremos explicar por qué el desarrollo y la globalización se apoyan en la pobreza para alcanzar sus objetivos, que se identifican con los del capitalismo: la obtención de los máximos beneficios posibles. Y cuál es el modelo de economía que propugna la sociedad actual basada en valores sincréticos humanistas. La economía social, la empresa con responsabilidad social empresarial y el mercado basado en el comercio justo, son la propuesta de un nuevo concepto de la economía global.

Es muy posible que la propuesta esté más dentro de la utopía que de una realidad posible. Pero el hombre ha buscado siempre un ideal que le acercara lo más posible a la perfección, aun cuando supiera que nunca llegaría a alcanzarla. La globalización, el

\footnotetext{
${ }^{1}$ Universidad de Valladolid. Dirección de correo electrónico: elenaig@eco.uva.es

${ }^{2}$ Universidad de Valladolid. Dirección de correo electrónico: manolo@eco.uva.es

REVESCO No 116 - Tercer Cuatrimestre 2014 - ISSN: 1885-8031 - www.ucm.es/info/revesco

http://dx.doi.org/10.5209/rev_REVE.2014.v115.45280

Fecha de recepción: 11/04/2014

Fecha de aceptación: 08/05/2014
} 
desarrollo, la competitividad, el mercado liberal y los objetivos centrados en los beneficios del capital, son factores que han estructurado el mundo empresarial globalizado, pero no implica que sea necesario mantener las mismas líneas de actuación, todo lo contrario.

El mundo que viene pretende ser el de la autogestión, la producción justamente retribuida, el mercado justo, la cooperación en la gestión y la democratización de las decisiones. Y como el sistema está globalizado, la economía también lo está y los productores ofrecen sus servicios en cualquier país del mundo, se globalizarán también los nuevos valores. Las empresas deberán adaptarse porque los mercados las forzarán, ya que ellos serán condicionados por la nueva ética de la sociedad. Seguramente no será un sistema perfecto ni logrará implantarse completamente, pero la presión que ejerce será siempre será positiva.

Palabras clave: Deslocalización, autogestión, sostenibilidad, cooperativismo, responsabilidad social, mercado, sociedad.

Claves Econlit: F680, M140, P130

\title{
REFLECTIONS ON GLOBALIZATION, POVERTY AND DEVELOPMENT: IMPACT ON SOCIAL ECONOMY ORGANIZATION
}

\begin{abstract}
Globalization during the last two decades of the twentieth century and the elapsed years in XXI century, has become a reality in one way or another, settled the current economy and largely the living conditions around the world. It is directly related with development such as this has been a condition for that and globalization is the framework in which this development has been possible. Usually the development entails expansion thus with an increasingly broader market widening up to globalization. But in this macroeconomic equation where is poverty ? probably in the center of the interaction between globalization and development. Poverty is the necessary condition for development and thus for globalization.
\end{abstract}

This paper tries to explain why the development and globalization are supported in poverty to achieve their goals, which are identified with capitalism : that is obtaining maximum benefits and what is the economic model advocated by the actual society based in syncretic humanist values. The social economy, companies which incorporate social 
responsibility and fair trade based market are a proposal of a new concept of the global economy.

It is quite possible that the proposal is more in the utopia side than in the real one . But man has always sought an ideal as close to perfection as possible, even though he knows that he would never reach it. Globalization, development, competitiveness, liberal market and objectives based on capital gains, are all factors that have structured the globalized business world, but all this does not imply the need to maintain the same lines just the the opposite.

The world to come is meant to be that of the self management, fair remunerated production and trade, cooperation in the management and democratization of decision making. And in a globalized system, so is the economy. Producers offer their services anywhere in the world, the new values are also going global . Companies must adapt because the markets will force them as they will be conditioned by the new ethics of society. Is unlikely to be a perfect system nor implementation completely achieved, but the exerted pressure will always be positive

Keywords: Relocation, self-management, sustainability, cooperatives, social responsibility, market, society.

\section{INTRODUCCIÓN}

En 1983 en The Harward Busines Review, Ted Levit publicó un artículo, que devendría en famoso, titulado "The Globalizatión of Markets" en el que afirmaba que la globalización de los mercados ya había llegado y distinguía entre la corporación multinacional y la corporación global, de manera que si bien la primera operaba en diversos países ajustaba "los productos y sistemas de producción a cada uno de ellos a un coste relativamente alto", la corporación global actúa "a un coste relativamente bajo, como si el mundo entero, o las zonas o regiones más importantes, fuera una simple entidad: vende las mismas cosas y de la misma manera en cualquier lugar".

Lo que estaba planteando Levit era una nueva mentalidad en la globalización, porque este concepto era tan antiguo como el propio capitalismo. Y más que una nueva mentalidad, una remoción de las antiguas formas de entender el mercado global. La globalización fue practicada por los romanos en el Mediterráneo, entonces el mundo entero, por los portugueses 
y españoles con sus imperios coloniales y los ingleses y franceses posteriormente. El colonialismo no deja de ser una variante de la globalización.

Las tres últimas décadas del siglo $\mathrm{XX}$ fueron testigos de una reorganización de la economía global consecuencia, en buen parte, de una acumulación de capital que creó una fuerte necesidad de inversión y, también en buena parte, de una reorganización del estatus geopolítico que se había mantenido, más o menos, intacto, desde el final de la II Guerra Mundial.

La caída de la URSS no fue sólo la desaparición de un moderno imperio políticomilitar, sino que también la ampliación del capitalismo a nuevas áreas que, de hecho, completaban el dominio de un sistema económico en prácticamente todos los países del mundo, aun cuando con matices propios de cada país o área económica ${ }^{3}$. Áreas que se han evidenciado como los organismos transnacionales que definen zonas de interés preferente para grupos de países, más o menos federados, en una acción común con fuerte tendencia globalizadora: Unión Europea (UE), Asociación de Naciones del Sudeste de Asia (ASEAN), Tratado de Libre Comercio de América del Norte (TLCAN), Nuevos Países Industrializados Asiáticos (NPIA's), entre otros.

Subirá y Gurgui (2007) plantean que no puede entenderse ningún fenómeno económico sin considerar a la vez la economía, la agenda social ni la política medio ambiental, porque si no funciona la primera no se dan las otros dos.

La globalización lleva esta relación de los elementos que interactúan entre sí en los marcos citados a todos los ámbitos, sólo que afecta a unos o a otros de forma diferente, o dicho de otra manera. Los elementos que conforman la sociedad globalizada son asimétricos, con lo cual los beneficios o los costes de la globalización también es asimétrica.

Stiglitz, define la globalización como:

“...la integración más estrecha de los países y los pueblos del mundo, producida por la enorme reducción de los costos de transporte y comunicación, y el desmantelamiento de las barreras artificiales a los flujos de bienes, servicios, capitales, conocimientos, y (en menor grado) personas a través de las fronteras.” (2002: 37).

\footnotetext{
3 “...la economía mundial ya no es una sumatoria de economías nacionales, sino una gran red de relaciones con una dinámica autónoma" (Wolovick, 1990)
}

REVESCO No 116 - Tercer Cuatrimestre 2014 - ISSN: 1885-8031 - www.ucm.es/info/revesco 


\section{GLOBALIZACIÓN, POBREZA Y DESARROLLO}

De hecho Levitt en su artículo se refería a la globalización ${ }^{4}$ de los mercados pero en la actualidad nos hallamos ante la globalización de la producción, que ha incidido mucho más en las formas de explotación del hombre, en el deterioro del medio ambiente y en las crisis económicas que la más visible globalización de mercados.

Cierto que una parte de la doctrina sobre la materia habla de semiglobalización y de que aún en esta mitad de la segunda década del siglo XXI la mayor parte de la actividad económica es esencialmente estatal, o sea dentro de cada país, pero también es cierto que las grandes multinacionales tienen más del $50 \%$ de su producción, ventas, personal y activos fuera de los que hasta hace pocos años eran sus bases nacionales (Ghemawat, 2008).

Para esta expansión de los mercados en un primer término y la producción en un segundo y más preocupante, han sido necesarias la aparición de una serie de innovaciones que se han venido en agrupar bajo el concepto de Nuevas Tecnologías. Fundamentalmente son dos las tecnologías que han promovido la deslocalización de la producción y de las empresas: los avances en la comunicación y el abaratamiento del transporte. En los dos casos, junto con las innovaciones que han mejorarlo las dos tecnologías y creado campos que les han permitido una mayor fiabilidad y rapidez, se ha dado una reducción de costes que en ambos aspectos han sido espectaculares. En 1930 una conferencia telefónica entre Nueva York y Londres de tres minutos costaba 350 dólares de la época, hoy día el coste es de 40 céntimos de dólar (Ghemawat, 2008), siempre que no se usen alternativas como Skipe, que además de ser gratuitas permiten conferencias múltiples. Algo muy parecido ha ocurrido con los transportes que no sólo han incrementado el volumen transportado en un solo vehículo, sino que más rápido y más barato por tonelada transportada ${ }^{5}$.

\footnotetext{
4 “...es importante tener en cuenta que la mundialización y globalización no son exactamente lo mismo. La mundialización económica es uno de los resultados del sistema capitalista... La globalización económica, que se inscribe en el marco general de la economía mundializada, es un fenómeno relativamente nuevo que se basa en las capacidades de producción, distribución, intercambio y consumo mundial o en tiempo real, lo cual implica una importante movilidad de mercancías y de factores productivos." (Vilaseca Requena y Torrente Sellens, 2005: 63)

5 "Desde el punto de vista tecnológico, los costos de transporte y comunicación han bajado sustancialmente, y la velocidad con la cual se viaja y se transmite ha aumentado exponencialmente. Esto ha hecho posible crear nuevos sistemas de comunicaciones, dirección y control dentro del sector empresarial. Los grupos de diseño e investigación se pueden coordinar en diferentes partes del mundo; los componentes se pueden fabricar en el lugar del mundo que sea más barato y enviar a puestos de montaje que minimicen los costos totales. Los productos armados se pueden despachar rápidamente hacia donde sean necesarios a través de sistemas de fletes aéreos puntuales." (Thurow, 1996: 129)
} 
Todas estas nuevas facilidades han devenido en la búsqueda de mano de obra barata en países subdesarrollados con poca o ninguna legislación, respecto a la preservación del medio ambiente y la calidad de vida, por parte de las empresas de los países desarrollados y con grandes capitales que invertir en un mercado global. Muy posiblemente esta sea la esencia última de la globalización: la coordinación interactiva entre el mercado y los centros de producción en busca de los menores costes posibles y los máximos beneficios. Que por otra parte no deja de ser una constante en el sistema capitalista. La globalización es consecuencia de la evolución del capitalismo, es pues un proceso irremediable y se rige por los valores del capitalismo occidental, que básicamente son producción barata e imponer las perspectivas occidentales al mundo. (Gutiérrez Haces, 2002).

Y también ha sido una constante en el capitalismo utilizar sistemas agresivos para introducirse en un mercado, con lo que se convierten en una amenaza a las bases socioculturales de los países que integran el mercado a conquistar, y ha sido una constante asimismo agresiva los sistemas utilizados para la explotación de la mano de obra en función de una mayor reducción de costes, que se traducen en mayores beneficios, lo que es una amenaza directa a la economía y organización política de los países a los que emigra la producción.

La doctrina en general opina que las prácticas agresivas de las multinacionales menos comprometidas con los valores de la economía social, tanto afectan negativamente a los países de procedencia como a los de recepción, pero esto es un poco ingenuo o partidista. La agresión a la sociedad de un país de recepción por medio de una política de bajos costes en personal, no sólo distorsiona el mercado laboral y la dinámica social, sino que crea dependencias que implican una sujeción a las empresas extranjeras y sus condiciones. No digamos los atentados al medio ambiente con la complacencia, a veces interesada, de las autoridades locales. Cierto que en el país de procedencia se produce una destrucción de empleo a causa de las deslocalizaciones, pero estos países disponen de capacidad para generar nuevos puestos de trabajo y también de sistemas de protección al trabajador en paro, lo cual mitiga mucho el problema y prácticamente nunca llega a ser un problema límite.

Para Kearney (2004) las principales causas de la deslocalización son:

- Costes (40\%): Costes laborales y de infraestructuras. Impuestos y costes de regulación. 
- Entorno (30\%): Riesgos socio-económicos, infraestructuras, compatibilidad cultural, proximidad geográfica, seguridad de la propiedad intelectual.

- Recursos humanos (30\%): Tamaño del mercado laboral, grado de educación, experiencia y barreras de entrada.

Y Tanganelli (2010: 30) propone como motivos y condiciones para deslocalizar la producción obtener unos costes laborales inferiores y unas políticas fiscales más suaves. Cierto que también propone dos condiciones: estabilidad política, confianza en las instituciones, pero estas condiciones están en función de asegurar y dilatar en el tiempo las dos motivaciones.

Sánchez Márquez en una línea similar dice: “...a través de la deslocalización las empresas buscan situarse en mercados con mayores perspectivas de expansión, aprovechándose de su situación geográfica en algunos casos, y principalmente buscan abaratar aquellas partes de sus procesos productivos donde son muy intensivas en mano de obra poco cualificada, cosa que consiguen gracias a los bajos salarios relativos a la economía en la que se establecen.” (Sánchez Márquez, 2006: 8).

Aun cuando se admite que la globalización se asienta en un mercado cuyas necesidades son creadas para motivarlo y no responden, por lo general, a autenticas necesidades, se admite al tiempo que la deslocalización dinamiza un mercado del trabajo que, en la mayor parte de los países subdesarrollados, brilla por su ausencia o es pagado peor de lo que ofrecen las multinacionales. En buena parte es cierto.

Se defiende que los bajos sueldos que pagan las multinacionales directa o indirectamente aumentan a lo largo de los años, de manera que sueldos que podrían considerarse de miseria llegan a convertirse en sueldos dignos para el nivel de vida del país. Lo cual no es cierto, porque sólo se elevan los sueldos cuando el coste de la vida, a consecuencia del mayor circulante ante la avalancha de puestos de trabajo, aumenta hasta límites imposibles para el país. Y aun cuando en algunos casos el aumento de remuneraciones no tenga que ver con el coste de la vida, si la tiene por la presión de compra de las multinacionales que conduce a una demanda de trabajadores con el consiguiente aumento de sueldos, que bajan cuando no hay demanda de mercancía y consecuentemente de horas/trabajo. 
Todo ello ha conducido a un choque cultural y social sin redimir la pobreza, sino que en muchas ocasiones la ha aumentado; también ha significado un choque de economías entre los países desarrollados y subdesarrollados que nunca pueden ganar los segundos por pura dinámica capitalista. La situación de la masa laboral de los países subdesarrollados (y algunos no tan subdesarrollados como en el caso de China), es parecida a las masas laborales de la Inglaterra victoriana, de la Francia de principios de siglo XX o la de la España de la misma época, que se describe como una economía de subsistencia y sin posibilidades de cambiar la situación de los obreros por carecer de derechos, por ejemplo los sindicales ${ }^{6}$.

La trilogía globalización, pobreza y desarrollo si bien implica una relación directa entre la globalización y la pobreza, no siempre se suma el tercer componente, el desarrollo. La reducción de costes de producción a través de la globalización de la producción es del orden del 70 al 80\%, dicho de otra manera lo que en un país desarrollado produce una riqueza de 100, en un país subdesarrollado produce una riqueza de 20 o 30 Tanganelli (2010). Y la diferencia es lo que se pierde en el país desarrollado peor es lo que gana la multinacional ${ }^{7}$.

En un primer análisis, la deslocalización puede parecer que produce mayor riqueza en el país receptor, por cuanto implica un aumento del PIB del país y una mayor entrada de divisas, dado que la mayor parte de la producción de deslocalización significan exportaciones. Pero las ventajas están de parte de la empresa que deslocaliza, que reduce en un 70 u $80 \%$ los costes, mientras que la fuerza laboral de los países receptores no ve aumentado su nivel de vida y sí aumenta, por la inflación del circulante, el coste de vida.

Vázquez y Baquero (2005) aseguran que la globalización implica un proceso de integración que aumenta los intercambios de bienes y servicios "la internacionalización de los capitales y el aumento de la producción internacional de las empresas multinacionales" lo cual es cierto, pero esto no beneficia a los productores de los países receptores ni elimina la pobreza de las masas de estos entornos.

Martín y Schumann (1998) ya en una fecha tan temprana se posicionaban opinando que: "Siempre que las empresas transnacionales hacen fabricar productos sus productos allá

\footnotetext{
${ }^{6}$ Cuando Porter dice "En una economía globalizada, aunque suene a paradoja, muchas de las ventajas competitivas residen en determinados factores locales" (1990:46), se refiere precisamente a las condiciones económicas y sociales que se pueden encontrar en los países del tercer mundo.

7 “En la expansión de las empresas transnacionales también influye la competencia de los distintos gobiernos nacionales por atraer inversiones extranjeras. La inversión exterior reporta ventajas innegables para los países que la reciben, aunque también pueda originar problemas de muy distinta índole." (Nieto Solís, 2005: 217).
} 
donde los sueldos son más bajos y los gastos sociales o gastos de protección del medio ambiente ni si quiera existen, el valor absoluto de sus costes desciende. Pero con esto no solamente desciende el precio de las mercancías, sino también el precio de la fuerza de trabajo"

El desarrollo que se considera inherente a la implantación de empresas en países subdesarrollados y para estos, implica la adopción de economías liberales que en países con carencias básicas, tanto a nivel humano como en infraestructuras o derechos laborales, suele ser el camino más directo hacia una reducción de la renta disponible para las masas productoras.

La misma Organización Internacional del Trabajo (OIT) dice que "los países más abiertos a los mercados internacionales son también los que cuentan con una red más estrecha de políticas e instituciones laborales que protegen más a sus trabajadores de los efectos negativos de la globalización" (En Auer, Efendioglu y Leschke, 2008) Lo cual es cierto para los países que cita que son Bélgica, Holanda, Dinamarca, Irlanda y Suecia, en los que las políticas institucionales cubren las carencias de la economía liberal frente al paro o la seguridad social. Pero también lo es, en signo contrario, para los países subdesarrollados que no poseen estos sistemas de protección frente a la problemática de la globalización.

Posiblemente la globalización de la producción no sea a corto plazo un factor de pobreza, pero tampoco lo es de desarrollo real y, especialmente, no lo es de desarrollo social y humano. Y en muchos casos, si el país receptor se convierte, por las circunstancias que sean, en país de origen, o sea que se deslocalicen las empresas que previamente se habían instalado en el país, la debacle social con caída en una mayor pobreza es la situación que a largo plazo espera a los que se han llamado países emergentes. Sólo la inversión de las grandes multinacionales en políticas de Economía social pueden detener la tendencia a la explotación y a una recurrente pobreza en estos países subdesarrollados ${ }^{8}$.

\section{INCIDENCIA DE LA ECONOMÍA SOCIAL EN LA GLOBALIZACIÓN}

Una parte de la doctrina ha visto, desde finales del siglo XX y principios del XXI, la globalización como un efecto perturbador de los mercados, de las culturas, tradiciones y

\footnotetext{
${ }^{8}$ Nieto Solis (2005, p. 213) enfoca esta realidad aunque de manera muy diplomática. "No es posible afirmar con carácter general si las empresas multinacionales tienen efectos globalmente beneficiosos o perjudiciales para los países donde se instalan. Estos efectos suelen apreciarse más desde el punto de vista sectorial y pueden cambiar de tendencia con el paso del tiempo."
} 
economías de los países subdesarrollados además de una forma de explotación de las masas laborales de estos países (García, 2001).

Uno de los problemas que presenta la globalización es que no sólo comprende un marcado global y una producción sin fronteras, sino que también implica una globalización social, política ideológica y cultural. En definitiva que cubre todo el espectro de las actividades humanas.

Lo cual ha motivado fuertes controversias entre los partidarios y los detractores de la globalización y, más aún, entre los que le encuentran virtudes económicas y los que defienden los factores sociales y humanos negativos a ella asociados. Sampedro (2002) compara las dos tesis opuestas que se ha dado en dos importantes foros internacionales sobre la globalización y que explicitan las dos posturas de la doctrina. Por una parte El Foro Económico de Nueva York sostiene la siguiente Tesis: la globalización es la única vía para acabar con la pobreza y es inevitable porque es consecuencia del progreso técnico. Mientras que el Foro Social de Porto Alegre plantea su tesis sobre la base de que cuanto más crece la actual globalización, más ganan los ricos y en peor circunstancias económicas y sociales se encuentran los pobres y "bastaría orientar el progreso técnico hacia el interés social pensando en todos para organizar otra globalización y otro mundo mejor, que es posible."

En este último marco propuesto por el Foro Social de Porto Alegre, se propone un modelo que haga compatible el desarrollo humano y el desarrollo sostenible con los nuevos modelos económicos que la globalización tiende a imponer, y de hecho impone, en un mundo que ha dejado de tener referentes, en mayor o menor medida justos y exitosos, en otros modelos como el comunista, que si bien es cierto que no solucionó nada en los países en que se implantó, no dejaba de ser un contrapeso al capitalismo salvaje, contrapeso que hoy día es necesario crear desde posiciones humanitarias.

Esta nueva visión de la economía que prioriza la vertiente social de la misma, responde a un planteamiento más justo del desarrollo y que incide más en obtener beneficios para el conjunto de la sociedad que para la empresa. No niega el derecho de la empresa de obtener ganancias en función de las inversiones de capital, sino que defiende el reparto de los beneficios y de la riqueza producido entre todos los participes en el proceso económico.

Es difícil establecer el origen de la nueva Economía Social cuando han sido varios los factores que han influido en su desarrollo, entre ellos y muy especialmente, la nueva 
sensibilidad que la sociedad occidental en particular ha desarrollado frente al problema de la pobreza, el medio ambiente, las diferencias entre las clases sociales y un justo deseo de mejor reparto de la riqueza que comportaría una mejor calidad de vida.

A nivel local, especialmente en los países desarrollados de Occidente, esta filosofía está ya muy asentada y las empresas, de manera más relevante las multinacionales, han cambiado su política de "menores costes posibles en producción y gastos generales" aún que sea pasando por encima de los derechos de las masas productoras.

Esta nueva sensibilidad ha llegado a las empresas en forma de nuevos conceptos relativos a la responsabilidad social de las empresas (RSE). Dicha responsabilidad social, una presión de la sociedad occidental, ${ }^{9}$ ha sido adoptada por las empresas en tanto y cuando dicha presión actuaba y actúa sobre el mercado, boicoteando los productos de las empresas que sobreexplotan a sus trabajadores en los países subdesarrollados. Por ello:

"Cada vez son más las empresas que consideran que no es incompatible la obtención de beneficios en el largo plazo con una acción socialmente responsable, tanto en los países de las que son originarias como en terceros países donde operan, muchos de los cuales son países del sur.” (Moreno et al., 2010, p. 64).

Sin embargo es cierto que las empresas transnacionales no son culpables directamente de la pobreza, en todo caso son culpables de aprovecharse de ella, pero no han creado las condiciones estructurales en que aparece y, sobre todo, se perpetúa. Su responsabilidad social está en función de la ética de la sociedad que las ha creado y es, de hecho, su principal cliente. En este contexto se entienden más las conclusiones del Informe Ruggie que las Naciones Unidas publicó en 2008 y que proponía tres líneas de actuación para las organizaciones que aceptan la responsabilidad social empresarial: proteger, respetar y remediar.

\section{LA DESLOCALIZACIÓN EN FUNCIÓN DE LA POBREZA}

La deslocalización para el país receptor supone, básicamente, creación de empleo de baja calidad, contaminación del medio ambiente y, en buena parte, destrucción del mismo por la incapacidad del país receptor de combatir el deterioro. Pero de manera más destacada y

\footnotetext{
9 “La movilización social, producto de la modernización económica y social (urbanización, alfabetización, industrialización), supone cambios en las aspiraciones de los individuos y los grupos que elevan sus expectativas y demandas. Si las aspiraciones crecen con mucha más rapidez que la capacidad de una sociedad para satisfacerlas se produce una amplia separación entre la creación de necesidades y su satisfacción, lo que provoca grandes frustraciones sociales." (Mota Consejero, 2008: 25).
} 
como evidencia parte de la doctrina (Pralahad y Hart, 2002) la dependencia del entramado laboral del país receptor respecto a las multinacionales. Un ejemplo de esta situación es la India.

Y aún cuando la inversión extranjera aporta desarrollo a un país en una primera fase crecimiento económico, no es ni equilibrado ni sostenible porque se fundamenta en los costes, si estos suben, que con la inflación de circulante subirán necesariamente, las ventajas competitivas del país se reducen y las multinacionales dejan de interesarse deslocalizando hacia otros entornos más rentables ${ }^{10}$.

Ante esta estrategia empresarial para reducir los costes y aumentar las ventas y, con ello, los beneficios, es evidente que las deslocalizaciones se dirigen principalmente hacia los países subdesarrollados con masas laborales que puedan explotarse a bajo coste: el sudeste y sur asiático, América Central y del Sur, algo menos en la Europa del Este y en algunas zonas de África como Marruecos, Egipto y en general el norte islámico.

El total de personas que viven en la extrema pobreza en el mundo, según el Banco Mundial $^{11}$ es de 1.300.000 individuos. Los individuos que viven con menos de $2 \$$ al día es de 2.500 millones con una proyección para 2015 de algo más de 2000 millones.

Cierto es que la deslocalización en particular y la globalización por lo general no llegan plenamente a los países que soportan los mayores índices de pobreza extrema. Países como Níger, Malí, Burkina Faso, Burundí, República Centroafricana Liberia, Guinea o Sierra Leona, que figuran con índices de pobreza extrema que va del 60 al 80\%, no son los países donde ha llegado con fuerza la globalización y menos las empresas han llevado sus equipamientos de producción para aprovechar una mano de obra misérrima.

Lo cual responde a una motivación por cuanto la globalización necesita mercados mínimamente rentables y un país con personas que disponen de menos de 1,25\$ al día, difícilmente pueden considerarse un mercado. Y la deslocalización necesita de unas mínimas infraestructuras de carreteras y transportes, una cierta capacidad industrial y empresarial que permita a los agentes locales convertirse en proveedores y una mano de obra barata pero con

\footnotetext{
10 "En este contexto, planteamos la tesis de que las relaciones humanas, y estas con respecto de la naturaleza, están ahora "teñidas de capital", lo cual ha convertido nuestro planeta en un inmenso campo de explotación. Considerando esa idea, puede entenderse fácilmente que la globalización de las relaciones capitalistas de producción es un proceso histórico que ha transformado al mundo - en virtud de la ley del valor mundializadaen una gigantesca factoría de generación de plusvalor y excedentes." (Romero Reyes, 2010: 32)

${ }^{11}$ Cifras publicadas en 2011 y referidas al 2008.
} 
un cierto nivel productivo o capacidad para adquirirlo en breve tiempo, lo que no ocurre en los países citados. Lo cual evidencia que hasta en la pobreza extrema existen niveles.

Es precisamente en el segundo y tercer nivel de la pobreza o sea el nivel medio y alto, aquellos que viven con entre 450 y $720 \$$ y entre 730 y $1500 \$$ al año, que se calculan en algo más de 2.750.000 es donde la deslocalización halla su elemento laboral natural. Estos países se concentran el Asia Meridional, con la India en primer plano, aun cuando hay grandes bolsas en dicho país de extrema pobreza, América Latina y África Suroccidental. Son países que disponen de infraestructuras, una población con cierta capacidad de producción y unas empresas locales suficientemente desarrolladas y con las calidades mínimas como para servir de proveedores.

Cierto que para Pralahad y Hart (2002) la base de la pirámide está formada por cuatro mil millones de personas, o lo estaba a finales del siglo XX -en este momento rondarían los tres mil millones)- y que se mantenían por debajo de los cuatro dólares diarios de disponibilidad y esta base es un mercado potencial y un semillero de mano de obra. Incluso el propio Pralahad (2006) insistió en que a los pobres había que dejar de verlos como un problema para percibirlos como una oportunidad, dejar de hacer caridad con ellos y convertirlos en clientes y propuso el lema "comerciar, no ayudar", lema que por otra parte proponen también los países pobres, aunque con un ligero matiz: comerciar con la producción del país, no sólo con lo que el país importa.

Una parte de la doctrina sigue este principio de Pralahad de una globalización intensa en los países pobres de manera que, adaptándose a sus costumbres y tendencias, venderles los productos, dicho de otra manera: a partir de un producto realizar las versiones locales necesarias sean cambios estéticos en el propio producto, de función o de marketing. Con lo que el país pobre se convierte en un mercado para las multinacionales y se globaliza ${ }^{12}$.

Cierto que una bolsa de pobreza consume, pero también lo es que consume muy poco y la aplicación de las medidas de una economía liberal, en la que se promueve el gasto como

\footnotetext{
12 "La modernización implica una diversificación de las actividades económicas, un aumento considerable de la especialización ocupacional y del uso de capital con relación a la mano de obra, la pérdida de importancia del sector primario de la economía respecto al sector industrial, comercial y de servicios, la sustitución de la agricultura tradicional por la agricultura comercial, y el desarrollo de mercados e instituciones nacionales... Estos cambios discurren en paralelo a la expansión de la alfabetización, de la educación y de los medios de comunicación de masas." (Mota Consejero, 2008: 23)
} 
panacea para la expansión de la economía, no es la mejor receta en una economía depauperada. Otra cosa es cómo se implementa un desarrollo sostenible.

Hammond et al. (2007), describe a la población de rentas bajas, la pobreza de la base de la pirámide, a través de las características que le adjudican: economía informal, necesidades básicas no cubiertas y penalización de la pobreza, por cuanto pagan por productos baratos pero sin calidad, dado que las empresas no encuentran rentable aumentar una calidad que el cliente no puede pagar. No es una mala descripción de las características, por lo menos las económicas, de la pobreza, pero el problema no es tanto de desarrollo económico como de desarrollo social y la solución no está en un mercado de consumo abierto a las multinacionales, sino en una economía social dirigida a la creación de riqueza entre los más pobres para mejorar sus condiciones de vida. No buscar venderles productos pensados en su capacidad económica, sino proporcionales instrumentos financieros y económicos para que puedan salir de la pobreza y mejorar su calidad de vida, por ejemplo el instrumento de las microfinanzas.

\section{LA ECONOMÍA SOCIAL Y SOLIDARIA}

“Lo que necesitamos es un equilibrio entre los costo conjuntos de valores -económico, ético, emocional y espiritual- que tenga como objeto de enfoque a la humanidad. Los llamaremos "valores humanos universales" Deberían ser aceptables para la mayoría de los humanos y servir como señales para el nuevo mundo "post-postapocalíptico". (Raich y Dolan, 2009:167).

Se ha querido ver la economía solidaria como aquella que busca un aumento de los emolumentos de los trabajadores que les permita llevar una vida digna dentro de su entorno social. O sea, que las retribuciones estarían en función del nivel de vida en que estos trabajadores se encuentren. Y ciertamente la economía solidaria quiere que la calidad de vida del trabajador sea digna. Pero la economía social no es sólo esto.

La economía solidaria implica un cambio esencial en las relaciones laborales entre empresa y productor, pero también entre sociedad y empresa y sociedad y productor. Y todo ello no sólo a nivel local sino también a nivel global. En la economía solidaria la expectativa de la empresa de obtener beneficios, sean a corto, medio o largo plazo, no es incompatible con las acciones sociales responsables. 
Este cambio de relaciones entre los agentes que configuran el mundo empresarial y la sociedad, se fundamenta en el concepto de que los únicos buenos negocios son aquellos que benefician a todos los estratos sociales (Austin, 2000). Yunus (2008) entiende que la beneficencia no es más que una forma egoísta de eludir la responsabilidad y es un instrumento de perpetuación de la pobreza, ya que impide que el pobre tenga iniciativas y trate de salir de su miseria. Yunus, fue el creador del Grameen Bank, entidad microfinanciera que tiene en Bangladesh más de 1.200 sucursales y más de tres millones y medio de clientes en 44.000 aldeas, que hacen uso de sus servicios, especialmente de los microcréditos ${ }^{13}$.

Promueve las organizaciones que actúan desde los planteamientos de la conciencia social y defiende ayudar a los empresarios concienciados que a la vez que compiten en el mercado para lograr una rentabilidad, tienen como primer y más importante objetivo el desarrollo sostenible y la economía social y ética.

Uno de los primeros retos con que se enfrenta la economía social es cambiar el paradigma de la competitividad, uno de los más arraigados valores de la economía capitalista. La competitividad es para la RAE "la rivalidad para la consecución de un fin" y para las empresa capitalista la herramienta que les permite luchar contra otras para lograr un mejor posicionamiento en el mercado, que deviene en mayores ventas $\mathrm{y}$, consecuentemente, en mayores beneficios.

Sin embargo, en una economía social y ética la competitividad es un valor muy relativo por no decir un instrumento de explotación. "La competitividad es la farsa para legitimar la desigualdad: se despide a la gente o se le rebaja el sueldo y luego se les dice que la causa es que no son competitivos" (Amin, 2014). Porque la competitividad, tal y como se entiende en una economía de mercado capitalista no es compatible con la economía social ${ }^{14}$. Cierto que en el ámbito de las empresas imbricadas en la economía social la competitividad es un factor que afecta a los resultados, pero no sacrifica a ella la responsabilidad social de la empresa ni los valores humanos. Las estrategias competitivas de las empresas de la economía social no pueden, pues, repercutir en el ahorro en los productores sino que deben arbitrarse

\footnotetext{
${ }^{13}$ Dan Bolt (2006) recuerda la declaración del Comité que concedió el Premio Nobel de la Paz a Yunus en 2006: "No es posible lograr una paz duradera a menos que los grandes grupos de población pobre encuentren modos de salir de la pobreza. Y los microcréditos constituyen un medio. El desarrollo de las capas bajas también sirve para fomentar la democracia y los derechos humanos"

14 "Lo que necesitamos es un equilibrio entre los costos conjuntos de valores -económico, ético, emocional y espiritual- que tenga como objeto de enfoque a la humanidad. Los llamaremos "valores humanos universales" Deberían ser aceptables para la mayoría de los humanos y servir como señales para el nuevo mundo "postpostapocalíptico." (Raich y Dolan, 2009:167)
} 
otros sistemas que permitan reducir los costes o convencer al mercado que existen unos precios justos, que es necesario asumir, y que una reducción de los mismos debe ser pagada por algún grupo de la cadena que va desde la materia prima hasta el consumidor. Y este grupo no puede ser otro que el más débil de la cadena.

La nueva empresa social y solidaria que asume la responsabilidad social como parte de sus objetivos, establece la realización del individuo en el trabajo que pasa por la desmercantilización del trabajo y del trabajador, la organización horizontal, las decisiones democráticas y la redistribución de los beneficios entre la empresa y los trabajadores. Lo cual lleva a una empresa cooperativista como expresión propia de la economía social, dado que en este tipo de empresas se presentan los cuatro factores que se han explicitado.

En las empresas cooperativas existe una toma de decisiones de tipo democrático, por lo menos en la Asamblea General en la que participan todos los socios, que por regla general son todos o prácticamente casi todos los trabajadores. Cierto que la participación democrática es la adopción de las grandes decisiones, ya que los órganos ejecutivos llevan el día a día de la empresa, pero los que controlan estos órganos ejecutivos también son elegidos democráticamente por dicha Asamblea General.

Respecto a las retribuciones, las cooperativas tienen dos sistemas, el primero los sueldos en función del puesto de trabajo. Estos emolumentos no son iguales ni hay razón alguna para que los sean, siempre referidos a puestos de distinta responsabilidad y conocimientos. Pero el segundo sistema se refiere al reparto de beneficios que está en función de las participaciones que retiene cada cooperativista y que suelen ser en función de la aportación o repartidas igualitariamente en el acto fundacional de la cooperativa.

El modelo de autogestión significa que todos los trabajadores se sientan implicados y responsables en la gestión de la empresa, con lo que los problemas de productividad si bien es posible que no desaparezcan del todo se reducen mucho. La asunción democrática de las decisiones permite una mayor claridad en la gestión, la producción y la política laboral, que implica un control de la Asamblea no sólo de los mandos de la empresa, no olvidemos que son elegidos, sino también de los trabajadores. Y el compartir la propiedad de forma igualitaria responsabiliza a todos los integrantes y les implica en una acción común.

Es la forma más depurada de la empresa social y, consecuentemente, un factor de potenciación de la economía social. 


\section{CONCLUSIONES}

Raich y Dolan (2009), como ya hemos visto, proponen un equilibrio de los diversos factores que inciden, hoy día, en la globalización de los mercados y la producción, equilibrio entre lo económico, ético, emocional y espiritual, con un enfoque humanitario y lo llama "valores humanos universales".

Con lo cual están proponiendo la fundamentación teórica de una nueva filosofía para sustentar los nuevos valores, o más bien la necesidad de nuevos valores, que se correspondan a un mundo globalizado.

Posiblemente el problema crucial sea este: la falta de una base ética que permita estructurar una sociedad global que integre las sociedades locales sin desplazarlas, a la vez que protege a sus componentes de las agresiones de la globalización. Y para ello debe convencerse a todos los agentes que de una manera u otra actúan en el marco de la economía en general, en la globalización, en los mercados y en las empresas, que reconviertan sus líneas de actuación y las adecuen a una nueva filosofía que tiene mucho de Oriente, se ha perfeccionado en Occidente y debe aplicarse principalmente en el actual Sur: el humanismo. Los agentes de esta realidad son los estados, las multinacionales, el mercado, la sociedad y las clases trabajadoras en general, pero especialmente de los países subdesarrollados.

Los estados cuyas estructuras actuales comenzaron a desarrollarse en el siglo XIX y alcanzaron su plenitud en el siglo XX, hoy día pierden soberanía y fuerza, tanto militar como económica, y ceden ambas a organizaciones supranacionales que tienden a controlar amplias áreas geo-económicas y geo-estratégicas. La Unión Europea es una y sirve como ejemplo, pero incluso en áreas más pequeñas desde la perspectiva geográfica, no así económica, también se dan estas comunidades de intereses, por ejemplo, el Consejo de Cooperación del Golfo Arábigo, cuya unión responde más a una preocupación estratégica que económica.

Si los estados, entendidos como durante la mayor parte del Siglo XX, están en recesión, las empresas multinacionales se han configurado como las organizaciones que dominan las áreas económicas y las explotan por encima de los intereses de los estados, sean propios o extraños. Estos conglomerados macroempresariales son los que condicionan las tendencias del mercado global e interaccionan con los gobiernos de los estados para lograr los menores costos de producción en función de los mayores beneficios. 
La incidencia de dichos conglomerados en los mercados es importante pero no es la única, la sociedad, otro de los agentes como se ha dicho, también los condicionan y los dirigen. La sociedad, que a través de ellos, de sus compras primando a un producto y desechando otro, es la última causa del comportamiento de dicho mercado. Un mercado que está íntimamente relacionado con la producción barata, pues sin ella no sería posible, y la producción barata con la explotación de las masas trabajadoras de los países más pobres, y todo ello posibilita una globalización que se ha dado en las dos últimas décadas del siglo XX y se da en las dos primeras del siglo XXI.

La globalización, hemos dicho, es una consecuencia del sistema capitalista y la explotación también es una consecuencia de dicho sistema y uno de sus componentes más esenciales es la competitividad, íntimamente relacionada con la explotación. Competir con un producto más barato, especialmente si hay que hacerlo en un mercado de poca capacidad económica, siempre ha sido la herramienta que han utilizado las empresas para hacerse con dicho mercado. Cierto que la calidad ha sido otra de estas herramientas y También la marca de prestigio, pero en cualquier caso, la producción barata ha sido el factor que ha determinado los beneficios.

El problema de la búsqueda de beneficios sin ninguna limitación ha sido, en el mundo occidental, contrarrestada por la capacidad del productor de defender sus derechos a través de organizaciones obreras. Lo cual si bien es cierto que conduce a la lucha de clases, más o menos civilizada, también lo es que logra un equilibrio en el que generalmente no gana nadie. Sin embargo, en los países subdesarrollados sin organizaciones obreras eficaces el obrero está indefenso. Obrero que ha encontrado una defensora en la sociedad occidental que es la misma que consume lo que produce a bajo precio.

La sociedad globalizada, principalmente la que tiene alta capacidad de compra, se ha escandalizado al comprobar que aquello que consume y por lo que paga altos precios, se produce con salarios de miseria. Lo cual ha provocado una reacción que está cambiando las bases del mercado, de la producción de las multinacionales y de la globalización hacia pautas más humanitarias en todos los niveles.

Este fenómeno ha conducido a la aparición de la Economía social, de las organizaciones de responsabilidad social empresarial y del desarrollo sostenible como factor asociado a la industrialización y consumo en una sociedad globalizada. Esta tendencia corre 
paralela a la ya antigua de la autogestión como paradigma de la economía social y solidaria. Este tipo de economía y de empresas asociadas es una propuesta para un nuevo modelo que, con el tiempo, puede llegar a globalizar un estilo tanto de empresa como de mercado justo.

De todos modos, a nuestro juicio estos planteamientos que son correctos en teoría y éticamente, están más cerca, en la práctica, de la utopía que de la realidad.

\section{BIBLIOGRAFÍA}

AMIN, S. (2014) Entrevista en La Vanguardia de Barcelona. Luis Amiguet 15/03/2014

AUSTIN, J. (2000) The Collaboration Challenge: How Nomprofits and Businesses Suceed through Strategic Alliances. San Francisco: Jossey-Bass.

CASAS, J. B. y TANGANELLI, D. (2010). La globalización como motor de procesos de regionalización económica: el caso de la euroregión del arco del Mediterraneo (EURAM). En TANGANELLI BERNADES, D. Globalización y procesos de internacionalización. Madrid: Civitas. Pág. 183.

DANBOLT, O. (2006) Presentation Speech for the Nobel Peace Prize 2006. Disponible en: http://nobelprize.org/nobel_prizes/peace/laureates/2006/presentation-speech.html

GARCÍA M. F. (2001). Anthony Giddens y la globalización en 'la tercera vía'. En: Globalización. Revista Web Mensual de Economía, Sociedad y Cultura.

GHEMAWAT, P. (2008). Redefiniendo la globalización. Bilbao: Deusto.

GUTIÉRREZ HACES, M. T. (2002). Procesos de integración económica en México y Canadá. Una perspectiva histórica comparada. México, D.F.: UNAM - Porrua.

HAMMOND, A., KRAMER, W., TRAN, J., KATZ, R. Y WALTER, C., (2007): The Next Four Billion: Market Size and Business Strategy at the Base of the Pyramid. Washington: World Resources Institute.

KEARNEY, A.T. (2003) Where to locate? Selecting a Country for Offshore Busines Processing. Chicago: Kearnay

MARTIN, H.P. y SCHUMANN. (1998). La trampa de la globalización. Madrid: Taurus.

NIETO SOLÍS, J. (2005). Organización económica internacional y globalización. Madrid. Siglos XXI.

MOTA CONSEJERO, F. (2008). Capital social y gobernabilidad. Madrid: Centro de

Estudios Políticos y Constitucionales.

SAMPEDRO, J. L. (2002) El mercado y la globalización. Barcelona: Destino.

PORTER. M. (1990). Ser Competitivos. Barcelona: HBR. 
PRAHALAD, C. K.. Y HART, S. (2002). The Fortune at the Bottom of the Pyramid. Strategy+ Business, 26: 54-67

PRALAHAD, C. K. (2006). The Fortune at the Bottom of the Pyramid. Pensylvania: Wharton School Publiching.

RAICH, M. y DOLAN, S. L. (2009). Más allá. Empresa y sociedad en un mundo en transformación. Barcelona: Profit.

ROMERO REYES, A. (2010). Elementos fundamentales para la teoría y estrategia de la transición socialista latinoamericana y mundial. Mayo 2010 http://rcci.net/globalizacion/2009/fg923.htm

SÁNCHEZ MÁRQUEZ, J. (2006). Análisis de un proceso de deslocalización industrial y propuestas de medidas correctoras. Proyecto final de carrera. Barcelona UPC.

STIGLITZ, J.E. (2002). El malestar de la globalización. Madrid: Taurus.

SUBIRÁ, A y GURGUÍ, A. (2007). Políticas para la competitividad. En Prólogo de Porter, M. H. Sobre la Competitividad. Barcelona: Antonio Bosch.

TANGANELLI I BERNADES, D. (dir.) (2010) Globalización y procesos de internalización. Navarra: Civitas/Thomson Reuters.

THUROW, LESTER C. (1996). El futuro del capitalismo. Cómo la economía de hoy determina el mundo de mañana. Buenos Aires, Argentina: Javier Vergara.

VÁZQUEZ BARQUERO, A. (2005). Las nuevas fuerzas del desarrollo. Barcelona: Bosch.

VILASECA REQUENA, J. y TORRENTE SELLENS, J. (2005). Principios de economía del conocimiento. Hacia una economía global del conocimiento. Madrid: Pirámide.

YUNUS, M. (2008) Un mundo sin pobreza: las empresas sociales y el futuro del capitalismo. Barcelona: Paidós Ibérica.

WOLOVICK, D. (1993). Globalización de la economía. En: Humanismo Latinoamericano. http://hlatino.com/htdocs/globalzeconom.htm. 